\title{
Integrated Starter Generator for 42-V Powernet Using Induction Machine and Direct Torque Control Technique
}

\author{
Amit Kumar Jain, Student Member, IEEE, Shashidhar Mathapati, V. T. Ranganathan, Senior Member, IEEE, and \\ V. Narayanan
}

\begin{abstract}
This paper describes an integrated starter generator (ISG) for automobile applications with $42-\mathrm{V}$ powernet. This system is based on an induction machine which is directly mounted on the engine crankshaft and controlled using the technique of direct torque control (DTC). The suitability of the technique for ISG application is explained. The control structure of DTC for ISG application is described. Detailed experimental results from a 1.4-1 diesel engine are presented demonstrating the performance of the system during cranking as well as generation. The ISG also incorporates the feature of "on the fly start" during generation mode. Details of a low voltage high current power converter developed for this application are also given.
\end{abstract}

Index Terms-Crankshaft mounted integrated starter generator (ISG), direct torque control (DTC) technique, induction machine, "on the fly start" (OTFS) mode, 42-V PowerNet.

\section{INTRODUCTION}

$\mathbf{T}$ $\mathrm{HE}$ current architecture of the electric power system in an automobile comprises a $14-\mathrm{V}$ bus and a $12-\mathrm{V}$ battery used to power 14-V loads. The $14-\mathrm{V}$ bus system has been in use since the mid-1950s. Automobiles prior to this time used a 6-V (with 7-V bus) system.

In the past two decades, the electrical power demand of automobiles has more than doubled, as more features are added to enhance comfort, convenience and safety. Fig. 1 shows the trends in power usage in passenger vehicles [1], [12]. Present full load power demand in the conventional passenger automobile is somewhere around 1.5 to $2 \mathrm{KW}$. It is anticipated that power need would rise to around 3 to $5 \mathrm{KW}$ in the near future.

The enhanced power requirement cannot be met with the present $14-\mathrm{V}$ system. The main reason is that the current to be handled by the conductor will exceed the safe value of about 200 A. $42 \mathrm{~V}$ (with $36-\mathrm{V}$ battery) has been internationally agreed upon as the safe powernet voltage for future automobiles [2], [3]. By using a 42-V bus system, a maximum power of about 9 KW can be safely handled without exceeding the limit of 200 A. One possible electrical architecture for the $42-\mathrm{V}$ system is shown in Fig. 2.

One important application of $42-\mathrm{V}$ powernet is the integrated starter generator (ISG). In conventional automobiles there is a

Manuscript received March 8, 2005; revised October 26, 2005. Recommended by Associate Editor J. Shen.

A. K. Jain, S. Mathapati, and V. T. Ranganathan are with the Department of Electrical Engineering, Indian Institute of Science, Bangalore 560012, India (e-mail: amitjain@ee.iisc.ernet.in).

V. Narayanan is with the Research and Development Division, Advanced Engineering Center, Lucas TVS Ltd., Chennai, India.

Digital Object Identifier 10.1109/TPEL.2006.872364

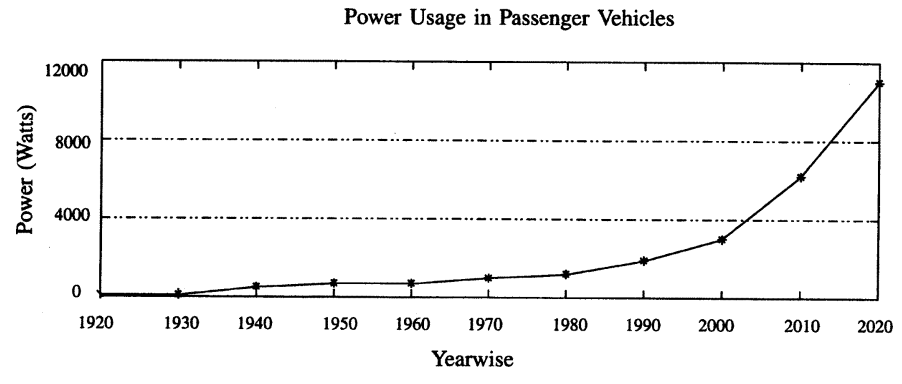

Fig. 1. Power usage in passenger vehicles.

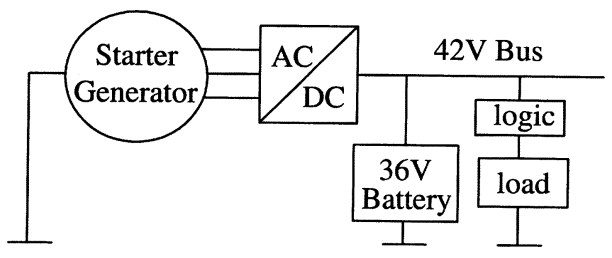

Fig. 2. 42-V architecture.

separate starter motor for cranking and an alternator for generation. The ISG combines the operations of alternator, the starter motor, flywheel and ring gear in a single unit. A single machine is used to perform both the functions of starter motor and alternator. There are many advantages and functions of ISG, some of which are listed below.

- The ISG control can start the engine within $200 \mathrm{~ms}$ (compared to $800 \mathrm{~ms}$ with de starter motor) [1]. It imparts an automatic stop/start capability to the engine. This allows the engine to shut down and avoid idling whenever the vehicle is stationary (also known as idle stop by some automotive manufactures) and restart quickly in response to the throttle pedal. This offers major savings in the fuel consumption (typically $10 \%$ to $25 \%$ ) and reduction in the emissions of $\mathrm{CO}_{2}$ (carbon dioxide).

- Additional high torque can be provided by the electric machine to the integrated circuit (IC) engine during acceleration (known as "power boost" or "electrical assist"). This allows the use of smaller, more-efficient internal combustion engines. Due to this feature ISG based engines are sometimes termed as mild hybrid.

- Energy recovery at braking by providing the ability to convert kinetic energy into storable electrical energy. This provides additional brake capability to the automobile.

Two types of 42-V alternators are now being developed. One is a belt-driven starter-generator that basically replaces the 


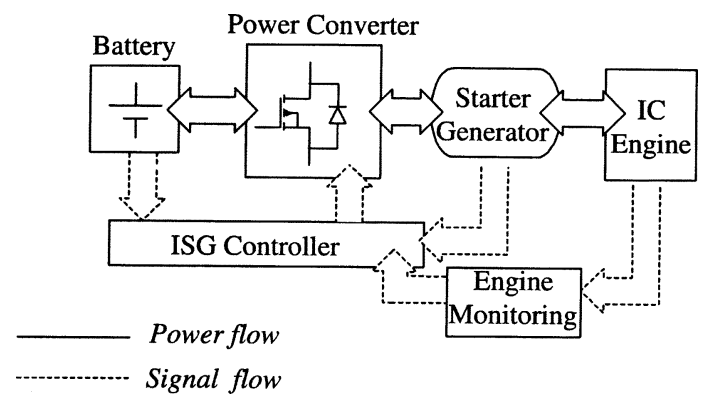

Fig. 3. Basic block diagram of ISG control.

present-day $14-\mathrm{V}$ alternator. Its output is generally under 5 $\mathrm{KW}$. The other is a crankshaft-mounted starter-generator (ISG) whose output is generally in the 5 to $12 \mathrm{KW}$ range. In the following, a crankshaft mounted ISG system, developed for a 1.4-1 diesel engine, is described.

This paper is organized as follows. The modes of operation for crankshaft mounted ISG are explained in Section II. Selection of induction machine and technique of direct torque control (DTC) for ISG application is described in Section III. Section IV describes the technique of DTC. It also explains the alterations required in the control structure for ISG operation. Section V gives the details of experimental setup. The description of low voltage high current power converter used for this application is given. Section VI gives the experimental results for ISG operation in different modes. It also give results for "on the fly start" (OTFS) mode of operation. Section VII gives the schematic showing gate drive and driver circuit arrangement for one leg of the power stage.

\section{CRAnkshaft Mounted ISG-Modes OF Operation}

The basic functional block diagram of ISG is shown in Fig. 3 . An ISG system typically contains a battery pack, a power converter, an electric machine, and controller for controlling ISG operation. The electric bus voltage is fixed to $42 \mathrm{~V}(14 \mathrm{~V} *$ $3)$ with a battery voltage of $36 \mathrm{~V}(12 \mathrm{~V} * 3)$. The batteries are lead-acid type with rating (AmpHours) depending on the charge requirement and size of the vehicle. The power module should be a low voltage high current converter to meet high starting torque requirement.

The ISG has four modes of operation. The changeover between different modes depends on operating conditions. At one time it can work in only one mode. The power flow in different modes of operation is shown in Fig. 4. The description of different modes is given below.

\section{Mode 1:-Engine cranking mode}

ISG operates in this mode, when the ignition switch is in the start position. Engine cranking mode is in effect when the engine speed is in between $0-150 \mathrm{rpm}$. During this mode ISG will provide sufficient torque to start the engine. Once the diesel engine fires the system accelerates; the control then transfers to one of the other modes.

Mode 2:-Running power generation mode

Once the engine has taken control over the system, ISG operation enters into power generation mode. In this mode the induction machine extracts power from the crankshaft and recharges the battery such that the bus voltage is maintained at $42 \mathrm{~V}$, irrespective of the load on the bus.

\section{Mode 3:-Braking power generation mode}

ISG control enters this mode, when the engine brake is $\mathrm{ON}$. It checks for the battery voltage. If the battery voltage is below $58 \mathrm{~V}$, then control operates in power generation mode and extracts maximum power from the engine and charges the battery. If the battery voltage is above $58 \mathrm{~V}$, then the ISG control enters into power dissipation mode. The power extracted is directed to power grid array to dissipate the energy.

\section{Mode 4:-Power boost mode}

ISG operates in the power boost mode, when the engine is running at low speeds (from 600-1000 rpm) and there is high acceleration demand (when the acceleration pedal is greater than $75 \%$ and the battery capacity greater than $50 \%$ of the rated capacity). In this mode, the induction machine will provide additional torque to the crankshaft to assist in acceleration.

The Mode- 1 and Mode- 2 are the basic operating modes. The system enters into the other modes when instructed to do so by suitable engine management system. In the following, therefore, operation in Mode-1 and Mode- 2 is mainly considered.

\section{Electric Machine AND TeChNiques of CONTROL}

DC machines have many drawbacks such as low power to weight ratio, high speed limitation, high maintenance etc. For automobile applications, maintenance is an important issue. Therefore, the trend is toward the usage of ac machines. Permanent magnet machines, even though more efficient, are very expensive for this application. They are also sensitive to high temperatures. Switched reluctance motors have various interesting features, but are sensitive to torque ripple, noise, and vibration. The control techniques are still evolving and require high resolution encoder. The induction machine, in contrast, is an established technology, provides higher efficiency and smoother torque with additional advantages such as ruggedness, low maintenance, high reliability etc. [4], [5]. Therefore, for this application an induction machine is selected.

Field-oriented control (FOC) and DTC are the two contending technologies for control of ac machines. FOC reestablishes the advantages of the dc drive through implementation of direct control of flux. DTC technique, on the other hand, has both direct flux and DTC loops.

Control of ISG with FOC has been reported widely in literature [6]-[8], while no publication is reported for DTC based ISG control.

Compared to the FOC technique, the DTC technique offers many advantages especially for ISG applications. These are discussed below.

- Cranking operation requires very high torque at starting. Also, fast dynamics is required typically in the range of few hundred of milliseconds. This duration decides the amount of charge drawn from the battery. Speed accuracy is not an important consideration during cranking.

- DTC technique is better suited for cranking operation as it offers excellent dynamics in torque control in a smooth manner during starting, compared to FOC.

- DTC scheme is very simple for implementation and requires less computational time. Therefore, higher switching frequency can be achieved. On the other hand, 


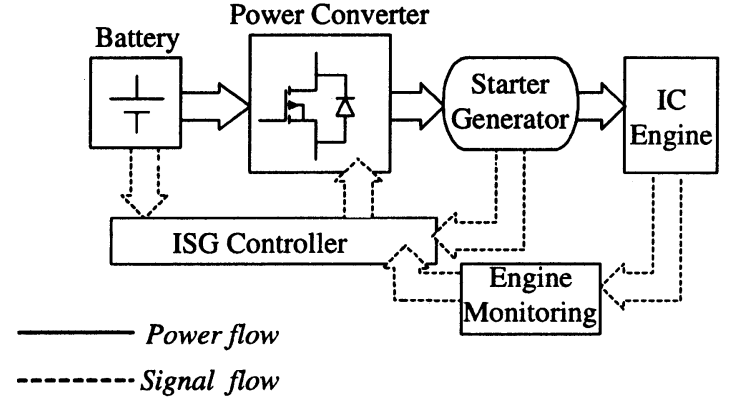

(a)

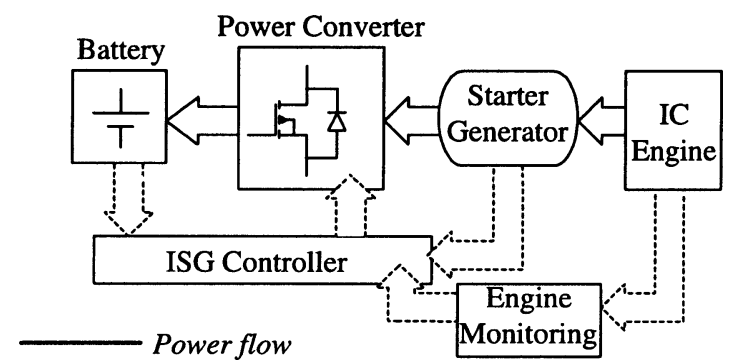

(b)

Fig. 4. Power flow direction in different modes of operation. (a) Mode-1 and Mode-4. (b) Mode-2 and Mode-3.

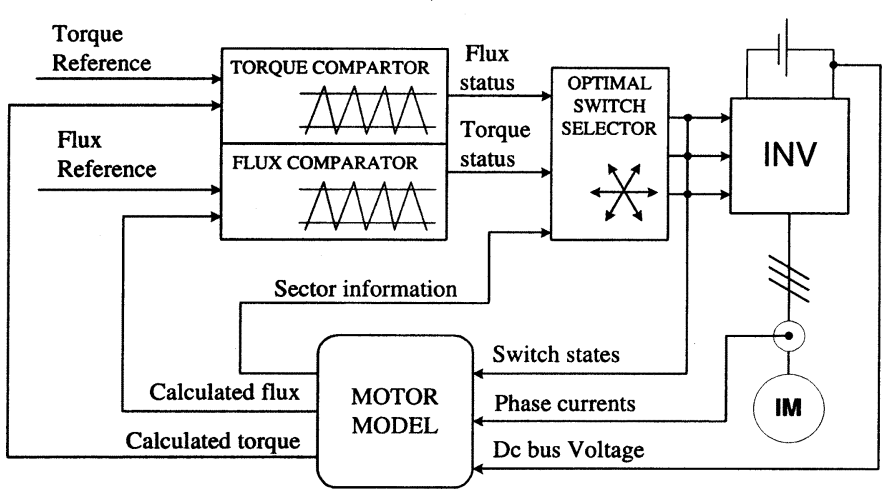

Fig. 5. Block diagram for DTC scheme.

FOC algorithm is complex and requires many routines which increases the total computational time.

- DTC technique requires the value of stator winding resistance only for the control, the measurement of which can be done with a simple self commissioning scheme. But the FOC control scheme requires all the parameters of the machine including rotor circuit values. There is possibility for parameter variation due to high temperature changes especially in automobile environment.

Considering all the features discussed above, the DTC technique has been adopted for the present work.

\section{DTC TECHNIQUE FOR ISG CONTROL}

\section{A. Basic Concept of DTC Technique}

The functional blocks used to implement the basic DTC scheme [9]-[13] are shown in Fig. 5. The core of the system is the direct torque comparator and flux comparator block with the optimal switching logic. The motor model estimates the actual torque and stator flux by means of measurement of two motor phase currents, dc bus voltage, and inverter switch positions.

Torque and flux references are compared with the actual values and control signals are produced using hysteresis comparators. Using these control signals together with sector information, switch references $(S a, S b, S c)$ for the power converter are generated.

In Fig. 6(a), the spatial vector orientation of stator and rotor flux in stator coordinates are shown. In Fig. 6(b), the six active switching voltage vectors and two zero vectors available form a two level inverter are shown.

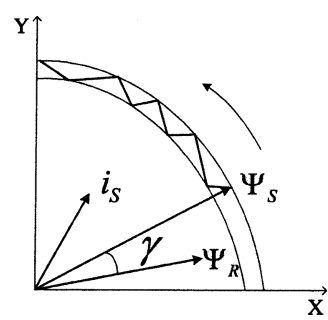

(a)

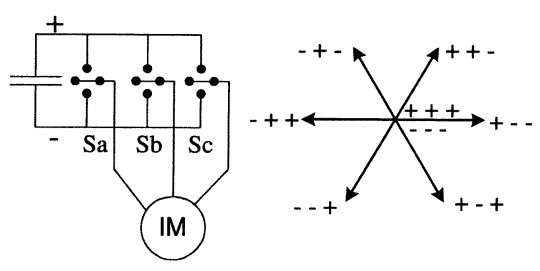

(b)
Fig. 6. Stator flux orientation and inverter switching voltage vectors.

$\psi_{S}$ and rotor flux $\psi_{R}$ as given by

$$
m_{d}=\frac{2}{3} \frac{P}{2} \frac{L_{O}}{\sigma L_{R} L_{S}}\left(\underline{\psi_{S}} \times \underline{\psi_{R}}\right) .
$$

If the magnitude of fluxes are kept constant, the motor torque can be controlled by adjusting the angle $\gamma$ between them. The rotor time constant is higher for a standard induction machine. DTC makes use of this property and achieves rapid control of torque by accelerating and decelerating the stator flux as fast as possible. The instantaneous value of stator flux is controlled by selecting a suitable state for the inverter. The optimal switching logic selects the best voltage vector.

\section{B. Motor Model}

The inputs to the motor model are stator phase currents, $\mathrm{dc}$ bus voltage, and inverter switch states.

1) Estimation of Stator Flux: The instantaneous stator flux is calculated using stator voltage vector $u_{S}$ and stator current $i_{S}$ using

$$
\underline{\psi_{S}}=\int\left(u_{S}-i_{S} R_{S}\right) d t
$$

The stator voltage vector is determined by measured dc voltage $U d c$ and actual inverter switch positions $(S a, S b, S c)$ using

$$
\begin{aligned}
u_{S \alpha} & =\frac{U d c}{2}[2 S a-S b-S c] \\
u_{S \beta} & =\frac{\sqrt{3} U d c}{2}[S b-S c] \\
u_{S} & =\sqrt{u_{S \alpha}^{2}+u_{S \beta}^{2}} .
\end{aligned}
$$




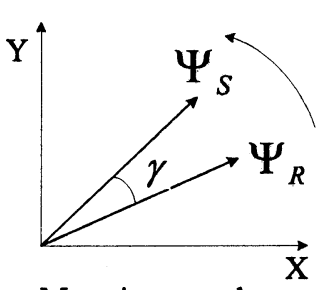

Motoring mode

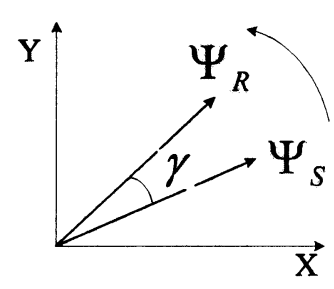

Generation mode
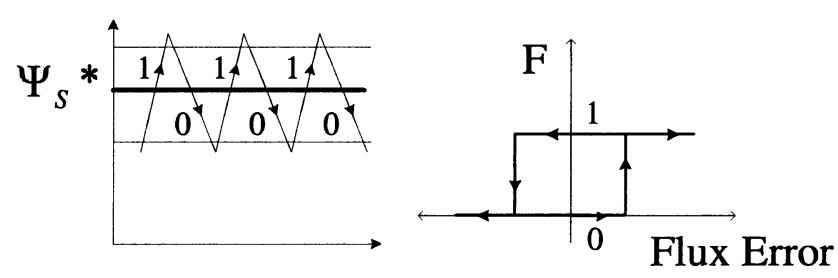

Fig. 7. Operation of flux comparator.

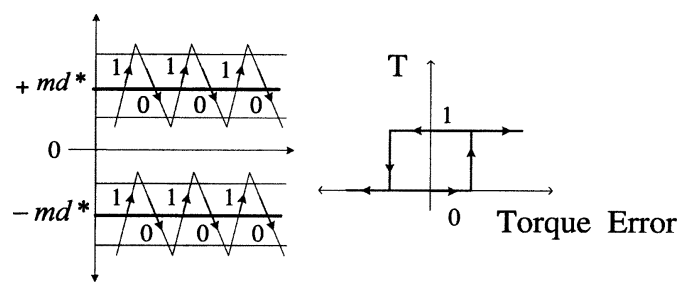

Fig. 8. Operation of torque comparator.

2) Estimation of Torque: The instantaneous value of torque can be calculated using a simplified equation [derived from (1)]

$$
m_{d}=\frac{2}{3} \frac{P}{2}\left(\psi_{S \alpha} i_{S \beta}-\psi_{S \beta} i_{S \alpha}\right) .
$$

3) Sector Information: Sector information can be estimated from the position of stator flux vector $\psi_{S}$ using instantaneous value of alpha-axis and beta-axis stator flux, namely $\psi_{S \alpha}$ and $\psi_{S \beta}$.

\section{Flux and Torque Controller}

Both flux and torque controllers are two level hysteresis comparators. Their operation strategy is described in Figs. 7 and 8. The flux comparator maintains the magnitude of stator flux in a defined band around the reference value once it is built up. The comparator checks for the flux error [reference flux-calculated flux] and outputs $F=1$ or $F=0$, depending on whether the flux error is positive or negative and outside the band. The two level comparator is sufficient as the direction of rotation of stator flux is same for both motoring and generation modes. The stator flux leads the rotor flux in motoring and lags in generation mode.

The operation of torque comparator is similar to flux comparator. It maintains the actual torque around reference value in a defined band. It checks for the error in torque and outputs $T=$ 1 or $T=0$. Condition $T=1$ leads to active voltage active vectors being applied; this results in acceleration of the stator flux. Condition $T=0$ leads to zero vector being applied; this keeps the stator flux stationary. In the motoring mode, as the stator flux leads the rotor flux, condition $T=1$ achieves increase in the torque magnitude while condition $T=0$ leads to decrease in the torque magnitude. In the generation mode, the stator flux lags the rotor flux, therefore condition $T=0$ will lead to increase in torque magnitude while condition $T=1$ leads to decrease in the torque magnitude.
TABLE I

OPTIMAL SWITCHING TABLE

\begin{tabular}{|c|c|c|c|c|c|c|c|}
\hline $\mathrm{F}$ & $\mathrm{T}$ & $\theta(1)$ & $\theta(2)$ & $\theta(3)$ & $\theta(4)$ & $\theta(5)$ & $\theta(6)$ \\
\hline 1 & 1 & 110 & 010 & 011 & 001 & 101 & 100 \\
\hline 1 & 0 & 111 & 000 & 111 & 000 & 111 & 000 \\
\hline 0 & 1 & 010 & 011 & 001 & 101 & 100 & 110 \\
\hline 0 & 0 & 000 & 111 & 000 & 111 & 000 & 111 \\
\hline
\end{tabular}

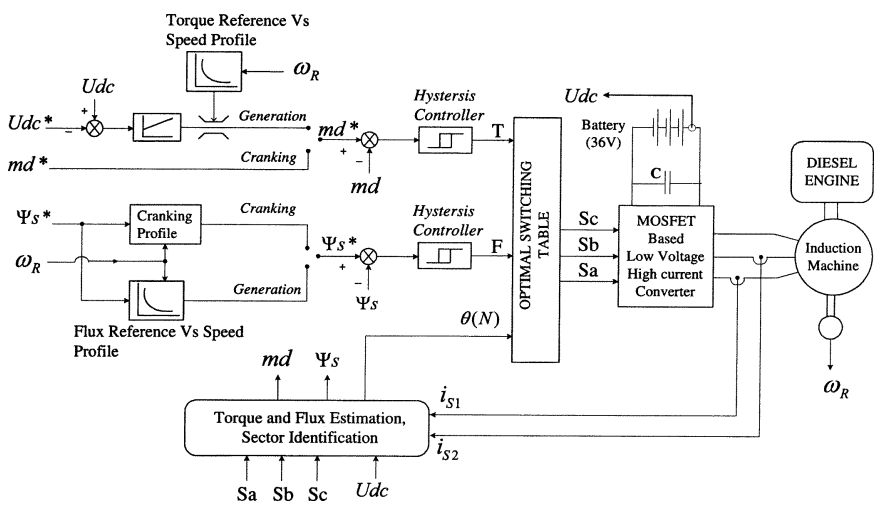

Fig. 9. Block diagram for DTC scheme for ISG application.

\section{Switching Table}

The switching table contains the inverter switching state information optimized for particular combinations of torque controller output [T], flux controller output [F], and sector information $\theta(N)$. The switching table is given in Table I. The switching table is evolved to ensure that there will be minimum switching between two consecutive samples, i.e., there will be no double switching.

\section{E. Control Structure for ISG Operation}

The basic core structure of the DTC technique is similar for the ISG operation. A few new blocks are added for estimating the suitable torque and flux references based on the operating condition, i.e., whether it is in motoring mode or generation mode. The control structure of DTC for ISG operation is shown in Fig. 9.

In the generation mode, an outer voltage control loop is closed around the torque comparator loop. The voltage loop regulates the dc bus voltage at $42-\mathrm{V}$ in generation. A limiter is added at the output of voltage PI controller to limit the torque reference value based on speed feedback. Torque reference is negative in generation mode. 


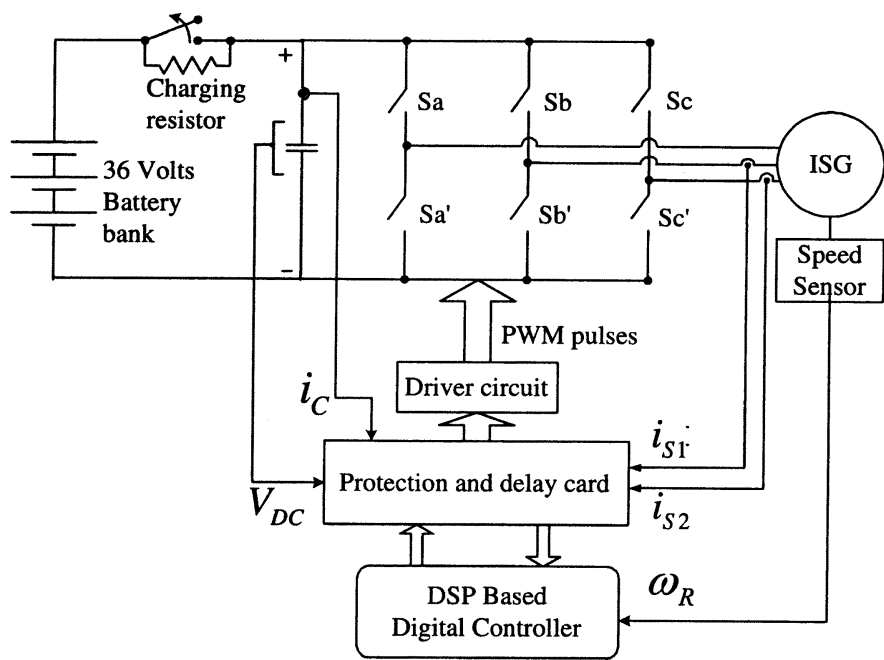

Fig. 10. Block diagram for ISG system.

In the cranking mode, flux reference is calculated based on a cranking profile. The profile keeps high flux reference for $100 \mathrm{~ms}$ such that high starting torque can be achieved for cranking. Once the diesel engine fires and the system accelerates, the flux reference calculation is based on speed feedback for both cranking and generation.

\section{EXPERIMENTAL SETUP}

Brief details of the experimental setup are given in this section. The block diagram of the experimental setup is given in Fig. 10.

To experimentally verify the ISG operation, a prototype of low voltage high current inverter was designed. Repeated tests on the system show that the maximum current required for the ISG application is around $1000 \mathrm{~A}$ (peak) with $42 \mathrm{~V}$. Since no single avialable device can meet this requirement, six MOSFETs [IR make FB180SA10 (100 V, 180 A, Rds(on) = $0.0065)$ ] are paralleled to realize a single switch. Paralleling of MOSFETs also decreases the ON state resistance of the equivalent switch. A total of 36 MOSFETs were required for the inverter. IR make drivers (IR2110) were used to drive the MOSFETs. Each driver chip drives two top and two bottom devices. Therefore three drivers are required for one leg and a total of nine drivers are required for the complete power converter.

The converter is protected against short-circuit and over-current. Short-circuit protection is done using feedback of capacitor current. Over-current protection is done using feedback of two phase currents. Current sensing is done using torodial ferrite CTs to avoid the cost of expensive hall effect sensors. DC bus voltage is sensed using a simple potential divider circuit. The pre-charging of the dc bus is done using resistor. Fig. 11 shows the photograph of the designed power converter.

\section{A. Controller}

The total ISG operation was implemented using a standard Texas Instruments TMS320LF2407 EVM DSP board. The total computation time required for executing all the routines is about

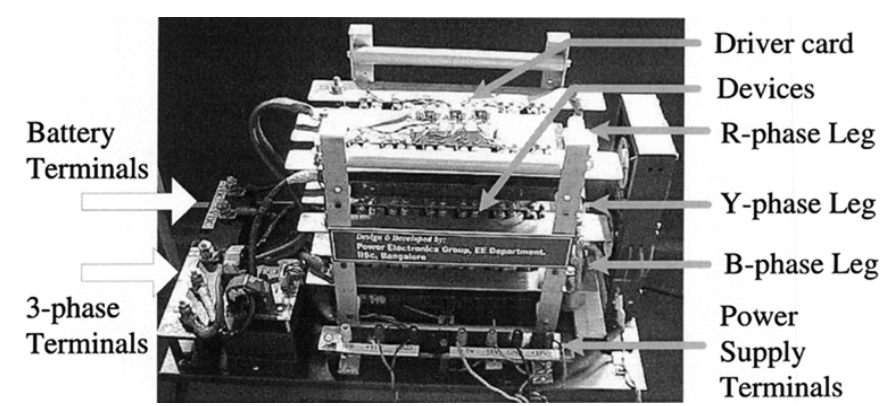

Fig. 11. Prototype of the developed power converter.

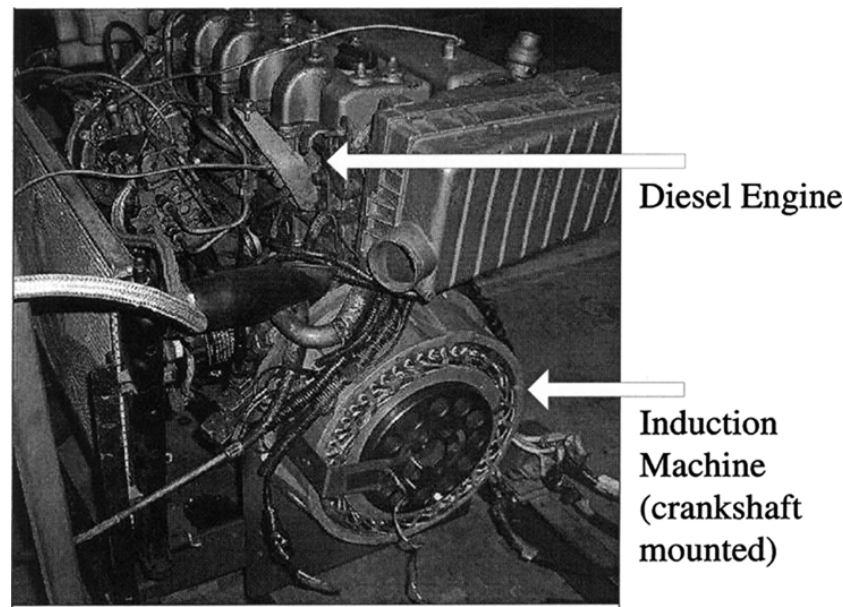

Fig. 12. Photograph of induction machine coupled to diesel engine crankshaft.

$30 \mathrm{~ms}$. The controller is enhanced by an interfacing card to accommodate the signal conditioning required for feedback signals to the ADC inputs and PWM signals.

\section{B. Induction Machine and Diesel Engine}

The induction machine has small axis, large diameter construction so that it can be easily mounted on the engine crankshaft without much modifications. Fig. 12 shows the photograph of the crankshaft mounted induction machine and diesel engine used for the experimental setup. The specifications of the induction machine and the diesel engine are given below.

\section{Induction machine:}

Three-phase, 22.2 V (Rms L-L), 200 A, eight-pole.

Diesel engine:

Type: Water cooled indirect injection.

No of cylinders: four inline.

Piston displacent: $1405 \mathrm{cc}$.

Maximum output: 53.3 PS at $5500 \mathrm{rpm}$.

Maximum Torque: $83 \mathrm{Nm}$ at $2500 \mathrm{rpm}$.

Compression ratio: 22:1.

\section{EXPERIMENTAL RESULTS}

\section{A. ISG Operation}

In the experimental tests, the main aim is to demonstrate the different modes of operation of crankshaft mounted ISG. The smooth changeover between modes is an important issue and 


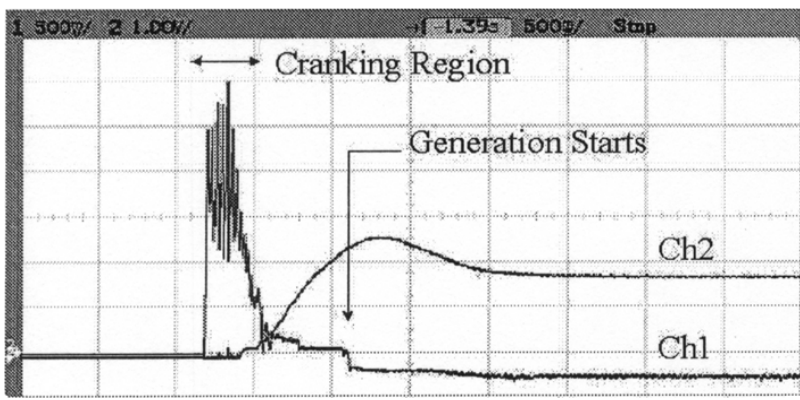

(a)

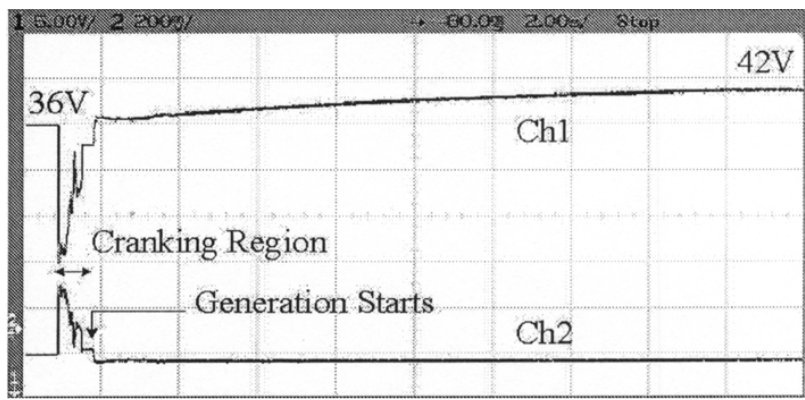

(b)

Fig. 13. (a) Ch1: calculated torque $\left(m_{d}\right)$ and Ch2: engine speed $\left(\omega_{R}\right)$. Torque Scale $=30 \mathrm{Nm} / \mathrm{div}$, Speed Scale $=500 \mathrm{Rpm} / \mathrm{div}$ and Time Scale $=$ $500 \mathrm{~ms} / \mathrm{div}$. (b) Ch1: battery voltage $(U d c)$ and $\mathrm{Ch} 2$ : battery current. Voltage Scale $=5 \mathrm{~V} / \mathrm{div}$, Current Scale $=400 \mathrm{~A} / \mathrm{div}$ and Time Scale $=2 \mathrm{~s} / \mathrm{div}$.

needs to be checked. Mode-1 (cranking) and Mode-2 (generation) are the main modes of ISG whereas mode- 3 (braking) and mode- 4 (power boost) are the sub-modes of mode- 2 and mode-1, respectively.

In this section, experimental results for mode- 1 , mode- 4 and mode- 2 are given. The changeover from mode- 1 to mode- 4 and mode- 4 to mode- 2 occurs in continous succession based on speed feedback. The engine is cranked using mode- 1 operation for about $100 \mathrm{~ms}$. Once the engine fires and diesel engine takes control of the system, ISG enters into mode- 4 at a speed of $150 \mathrm{rpm}$. In mode-4, the ISG assists the engine in acceleration. When the engine speed crosses $800 \mathrm{rpm}$, ISG enters into mode-2, i.e., power generation mode. It is also possible to switch off the DTC control after cranking and restart the control after engine speed reaches $800 \mathrm{rpm}$ using OTFS mode. This mode is explained in a later section.

In mode-1 (cranking) control of torque is achieved through the control of the flux comparator. The torque controller output $T$ is kept forced to 1 . Flux reference is calculated using a cranking profile. The profile keeps high flux reference for $100 \mathrm{~ms}$. The inverter operates in six step mode so that high starting torque can be achieved for cranking. In mode-4 (power boost), flux reference is calculated as a inverse function of speed such that frequency of the stator flux is adjusted according to the engine speed. In this mode both diesel engine and induction machine drive the system. In mode-2 (generation), the outer voltage loop starts operating and gives negative torque reference command at its output. Due to the negative torque reference, the ISG works in generation mode and extracts power from

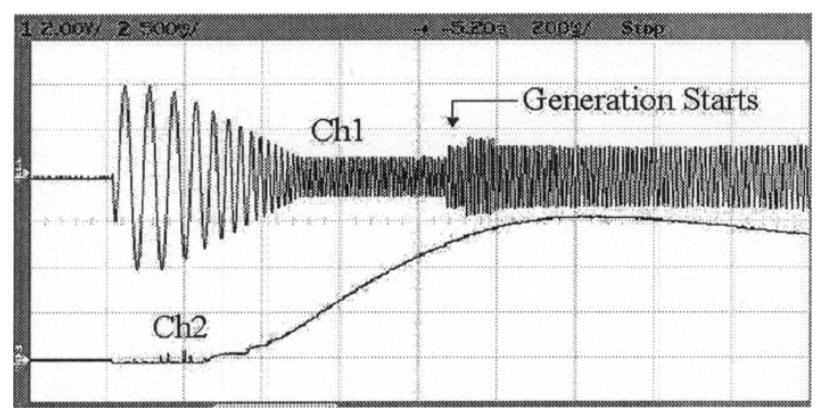

(a)

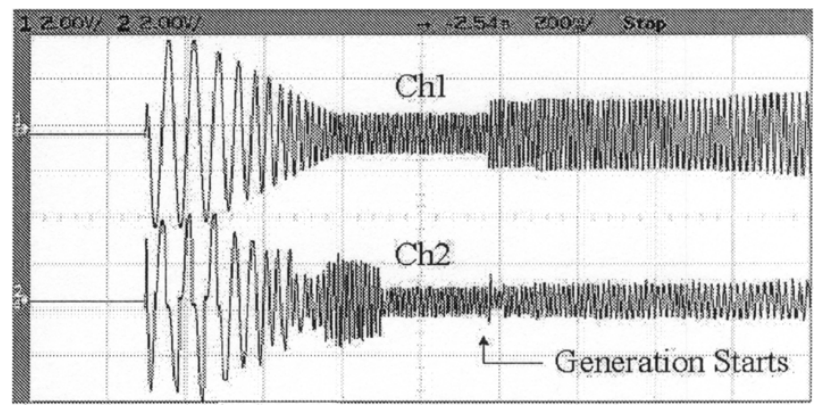

(b)

Fig. 14. (a) Ch1: alpha-axis flux $\left(\psi_{S \alpha}\right)$ and Ch2: engine speed $\left(\omega_{R}\right)$. Flux Scale $=0.05 \mathrm{~Wb} / \mathrm{Div}$ (cranking), $0.025 \mathrm{~Wb} / \mathrm{Div}$ (generation), Speed Scale = $500 \mathrm{Rpm} / \mathrm{Div}$ and Time Scale $=0.2 \mathrm{~s} / \mathrm{Div}$. (b) Ch1: alpha-axis flux $\left(\psi_{S \alpha}\right)$ and Ch2: stator phase current $\left(i_{S 1}\right)$. Flux Scale $=0.05 \mathrm{~Wb} / \mathrm{Div}$ (cranking), $0.025 \mathrm{~Wb} / \mathrm{Div}$ (generation), Current Scale $=400 \mathrm{~A} / \mathrm{Div}$ and Time Scale $=$ $0.2 \mathrm{~s} / \mathrm{Div}$.

the engine and charges the battery. ISG also maintains powernet voltage to $42 \mathrm{~V}$. The limiter at the output of the voltage controller controls the output power.

Fig. 13(a) shows the calculated torque and engine speed for entire ISG operation. The total cranking process takes about $200 \mathrm{~ms}$. The starting torque required for cranking is around $130 \mathrm{Nm}$. Full torque is achieved in about $1.5 \mathrm{~ms}$ itself. ISG operates in mode- 4 when the engine speed is between $150 \mathrm{rpm}$ and $800 \mathrm{rpm}$. ISG enters into generation mode at speed of $800 \mathrm{rpm}$. It can be observed that the calculated torque becomes negative in generation. The engine speed droops in generation mode due to absence of engine speed control mechanism.

Fig. 13(b) shows the dc bus voltage and battery current during ISG operation. Battery voltage drops by about $14 \mathrm{~V}$ (value depends on the battery charge condition) during cranking as high current is drawn from the battery in this mode. The maximum dc current drawn for cranking is about $500 \mathrm{~A}$. It can be observed that battery current becomes negative in generation mode and charges the battery at a current of about $40 \mathrm{~A}$. The battery voltage rises to $42 \mathrm{~V}$. The time required for attaining $42 \mathrm{~V}$ from $36 \mathrm{~V}$ depends on the torque reference limit; the higher the limit, the smaller time required for attaining $42 \mathrm{~V}$.

Fig. 14(a) shows the stator flux (alpha-axis) and engine speed. It can be observed that the peak value of flux is constant for about 100 ms during cranking operation. Flux magnitude is reduced as a function of speed after engine speed reaches $150 \mathrm{rpm}$. In the waveform the magnitude of the applied flux appears to be different when ISG enters into generation. This is due to different flux scale for motoring and generation modes. But the 


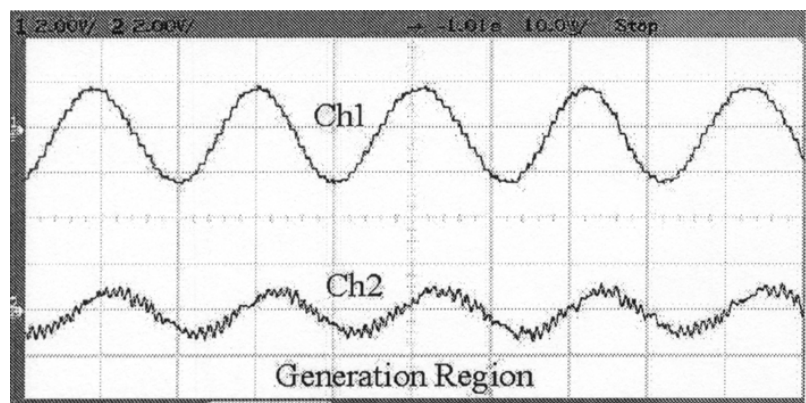

(a)

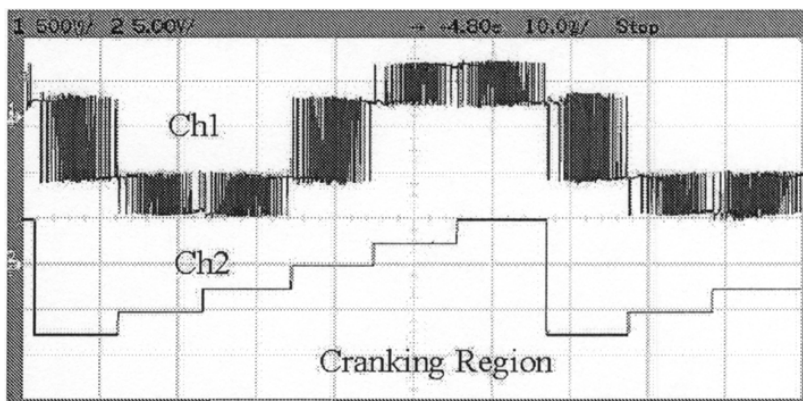

(b)

Fig. 15. (a) Ch1: alpha-axis flux $\left(\psi_{S \alpha}\right)$ and $\mathrm{Ch} 2$ : stator phase current $\left(i_{S 1}\right)$. Flux Scale $=0.025 \mathrm{~Wb} / \mathrm{Div}$, Current Scale $=400 \mathrm{Amps} / \mathrm{Div}$ and Time Scale $=$ $10 \mathrm{~ms} / \mathrm{Div}$. (b) Ch1: alpha-axis stator voltage $\left(u_{S \alpha}\right)$ and Ch2: sector information. Voltage Scale $=20 \mathrm{~V} / \mathrm{Div}$, Time Scale $=10 \mathrm{~ms} / \mathrm{Div}$

actual flux has same absolute magnitude for both motoring and generation.

Fig. 14(b) shows the stator phase current and stator flux. The starting phase current required during cranking is about $750 \mathrm{~A}$ peak. The phase current and stator flux are sinusoidal during entire operation. It can be noted that the transition between different modes is smooth without any transients in phase currents.

Fig. 15(a) shows the stator flux and stator phase current during generation mode. Phase currents are sinusoidal with superimposed switching ripple.

Fig. 15(b) and Fig. 16(a) show the calculated stator voltage (alpha axis) and sector information during cranking and generation modes respectively. The waveforms show that the DTC technique is functioning smoothly with all the six sectors attained neatly. Stator voltage changes in six step mode in cranking to achieve high starting torque [Fig. 15(b)]. In generation stator voltage vectors switch between active and zero states [Fig. 16(a)].

Fig. 16(b) show stator phase current and stator phase voltage during generation mode.

\section{B. OTFS Control}

One specific requirement of ISG system is OTFS mode. Any nuisance tripping of the ISG system (inverter) may cause loss of DTC control. The OTFS control mode is to used to regain the control without any necessity for restarting the engine. OTFS mode of control has been tested over a wide range of engine speeds (800 rpm to $5000 \mathrm{rpm})$.

To check and verify the OTFS mode the following procedure is adopted. Once the engine is cranked using mode-1, the DTC

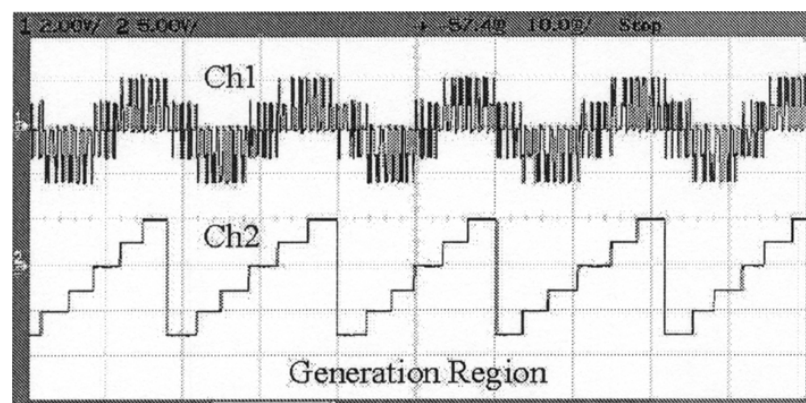

(a)

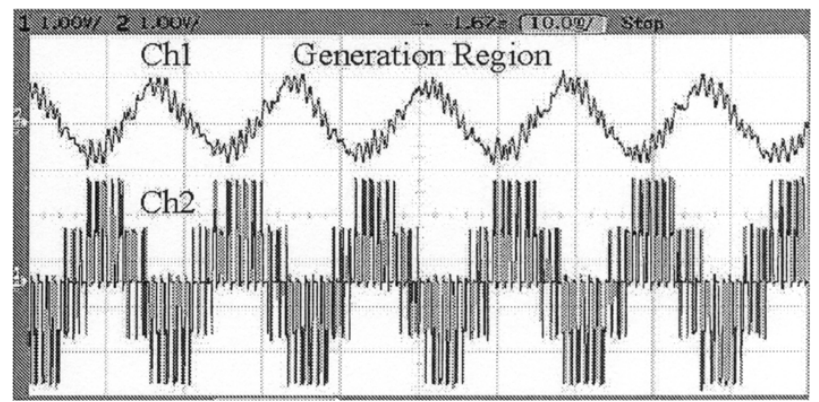

(b)

Fig. 16. (a) Ch1: alpha-axis stator voltage $\left(u_{S \alpha}\right)$ and Ch2: sector information. Voltage Scale $=20 \mathrm{~V} / \mathrm{Div}$ and Time Scale $=10 \mathrm{~ms} / \mathrm{Div}$. (b) Ch1: stator phase current $\left(i_{S 1}\right)$ and $\mathrm{Ch} 2$ : alpha-axis stator voltage $\left(u_{S \alpha}\right)$. Current Scale $=$ $200 \mathrm{~A} / \mathrm{Div}$, Voltage Scale $=10 \mathrm{~V} / \mathrm{Div}$ and Time Scale $=10 \mathrm{~ms} / \mathrm{Div}$.

is switched OFF. After the engine speed crosses $800 \mathrm{rpm}$, the control is restarted again in OTFS mode.

In OTFS control mode, initially stator flux is built by entering motoring mode with a small positive torque reference for $50 \mathrm{~ms}$. The control then transits to generation mode. The flux reference and torque reference in the generation are decided based on speed feedback as usual.

Fig. 17(a) and (b), shows the operation of OTFS mode. It can be noted that DTC is switched OFF after cranking and switched ON again after three seconds in OTFS mode.

Figs. 18 and 19 shows the experimental results where the operation of OTFS mode test is based on speed. The OTFS mode starts when engine speed crosses $800 \mathrm{rpm}$.

Fig. 18(a) shows that the calculated torque is zero between engine speed of $500 \mathrm{rpm}$ and $800 \mathrm{rpm}$. ONFS control mode starts the DTC after $800 \mathrm{rpm}$. Torque reference is positive for 50 miliseconds during ONTF mode to built up the flux.

Fig. 18(b) shows that stator flux is killed to zero at engine speed of $500 \mathrm{rpm}$ and built again in ONTF mode after $800 \mathrm{rpm}$ speed.

Fig. 19(a) and (b) shows stator flux and stator current during the entire operation. These waveforms show that overall transition is smooth in ONTF mode.

\section{Test Results for Power Generation Capability}

Generation capability of the induction machine is tested on a dynamometer test rig. Due to lack of engine management system this test was not done with the engine. Test results are shown in the Fig. 20. The graph shows the maximum power generated by the induction machine at different prime mover 


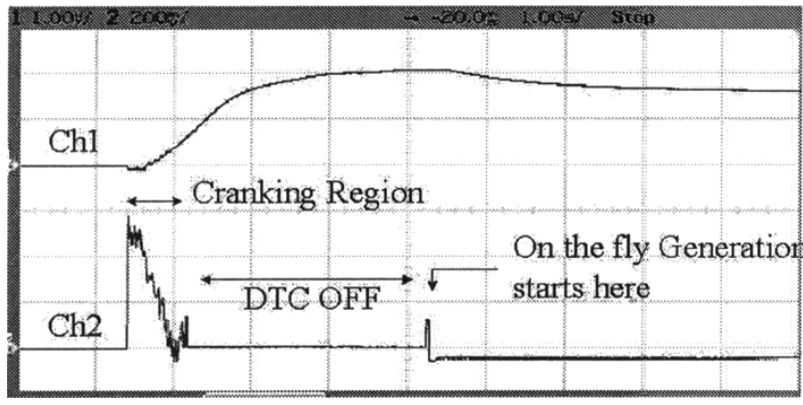

(a)

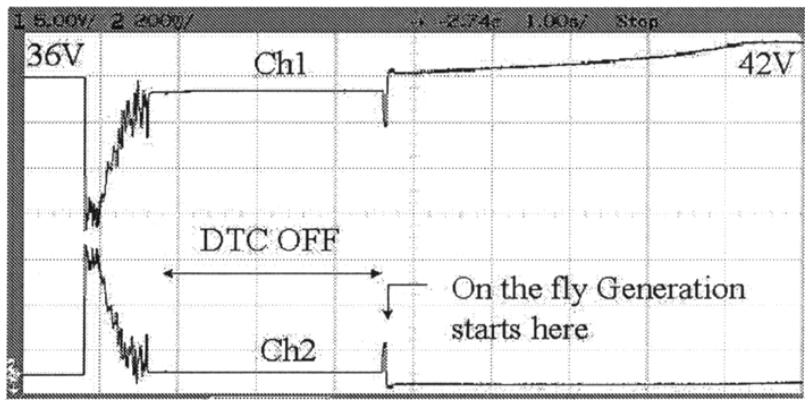

(b)

Fig. 17. (a) Ch1: engine speed $\left(\omega_{R}\right)$ and $\mathrm{Ch} 2$ : calculated torque $\left(m_{d}\right)$. Torque Scale $=60 \mathrm{Nm} /$ Div, Speed Scale $=1000 \mathrm{Rpm} / \mathrm{Div}$ and Time Scale $=1 \mathrm{~s} /$ Div . (b) Ch1: battery voltage $(U d c)$ and Ch2: battery current. Voltage Scale $=$ 5 V/Div, Current Scale $=200$ A/Div and Time Scale $=1 \mathrm{~s} /$ Div.

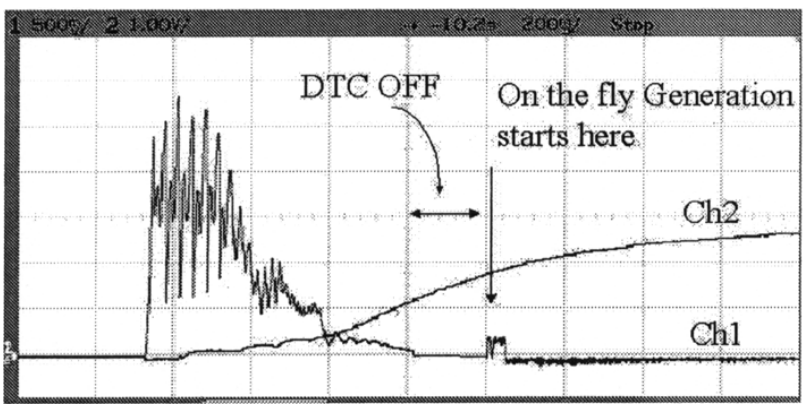

(a)

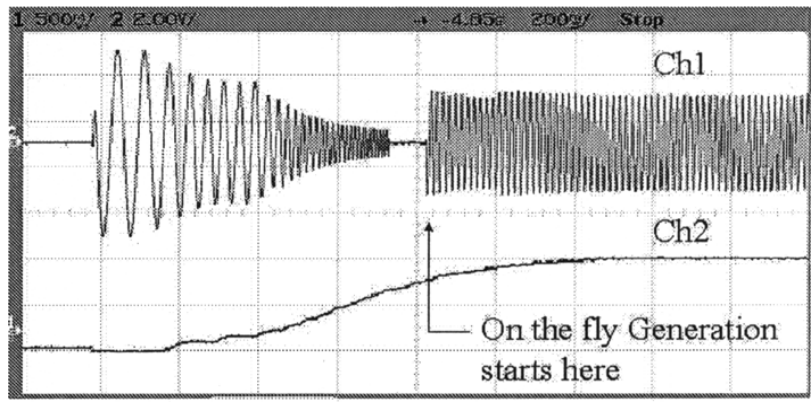

(b)

Fig. 18. (a) Ch1: calculated torque $\left(m_{d}\right)$ and Ch2: engine speed $\left(\omega_{R}\right)$. Torque Scale $=30 \mathrm{Nm} /$ Div, Speed Scale $=500 \mathrm{Rpm} / \mathrm{Div}$ and Time Scale $=200$ milliseconds/Div. (b) Ch1: alpha-axis flux $\left(\psi_{S \alpha}\right)$ and Ch2: engine speed $\left(\omega_{R}\right)$. Flux Scale $=0.05 \mathrm{~Wb} / \mathrm{Div}$ (cranking), $0.025 \mathrm{~Wb} / \mathrm{Div}$ (generation), Speed Scale $=500 \mathrm{Rpm} / \mathrm{Div}$ and Time Scale $=0.2$ Seconds $/$ Div .

speeds. It also shows the corresponding efficiency of the combined induction machine and power stage at different prime

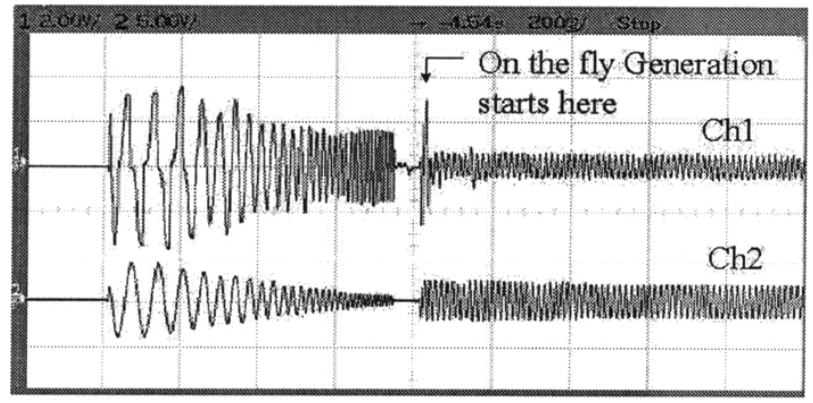

(a)

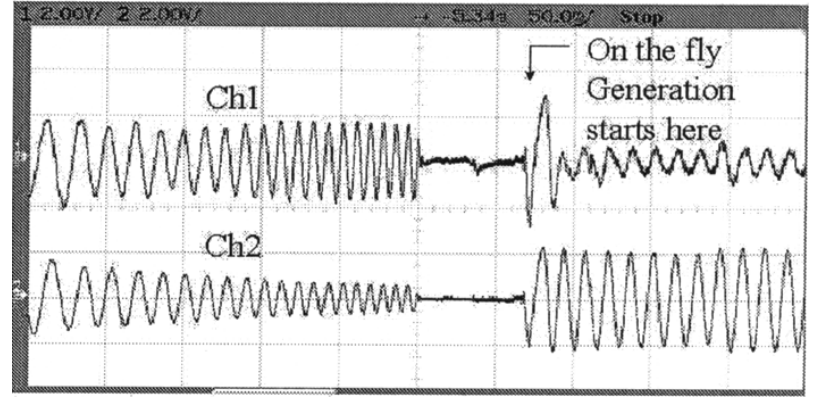

(b)

Fig. 19. (a) Ch1: stator phase current $\left(i_{S 1}\right)$ and Ch2: alpha-axis flux $\left(\psi_{S \alpha}\right)$. Flux Scale $=0.05 \mathrm{~Wb} / \mathrm{Div}$ (cranking), $0.025 \mathrm{~Wb} / \mathrm{Div}$ (generation), Current Scale $=1000 \mathrm{~A} / \mathrm{Div}$ and Time Scale $=200 \mathrm{~ms} / \mathrm{Div}$. (b) Ch1: stator phase current $\left(i_{S 1}\right)$ and Ch2: alpha-axis flux $\left(\psi_{S \alpha}\right)$. Flux Scale $=0.05 \mathrm{~Wb} / \mathrm{Div}$ (cranking), $0.025 \mathrm{~Wb} / \mathrm{Div}$ (generation), Current Scale $=400 \mathrm{~A} / \mathrm{Div}$ and Time Scale $=$ $50 \mathrm{~ms} /$ Div.
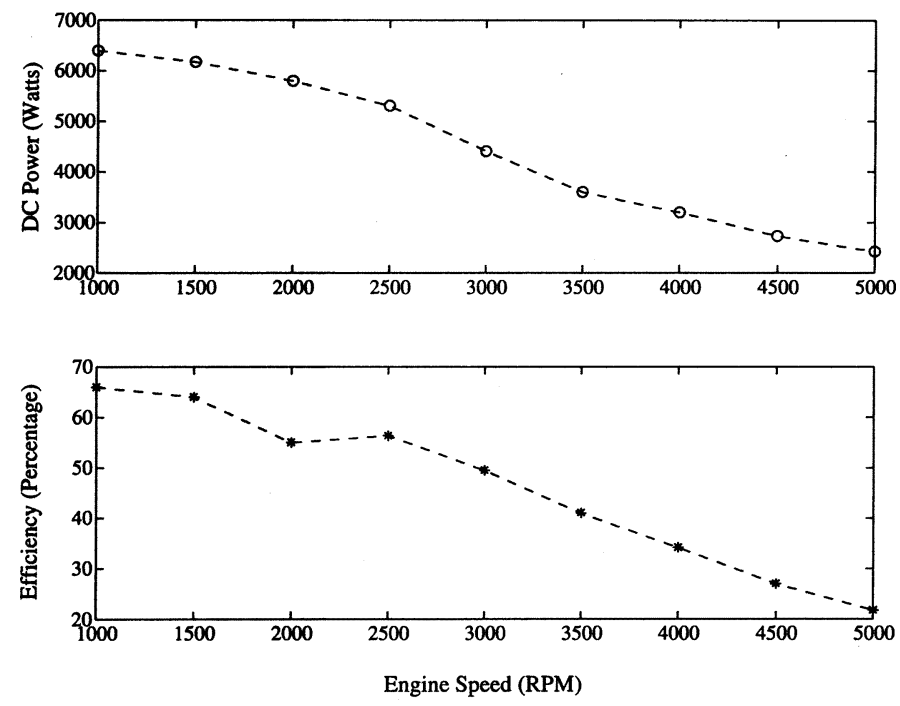

Fig. 20. Test results for the power generation capability and the corresponding efficiency of the induction machine at different speeds.

mover speeds. The control was started using OTFS mode of operation at different speeds of the prime mover.

\section{Summary of Test Results}

Summary of the ISG test results are listed in Table II.

\section{Gate Drive ARRANGEMENT}

See Fig. 21. 


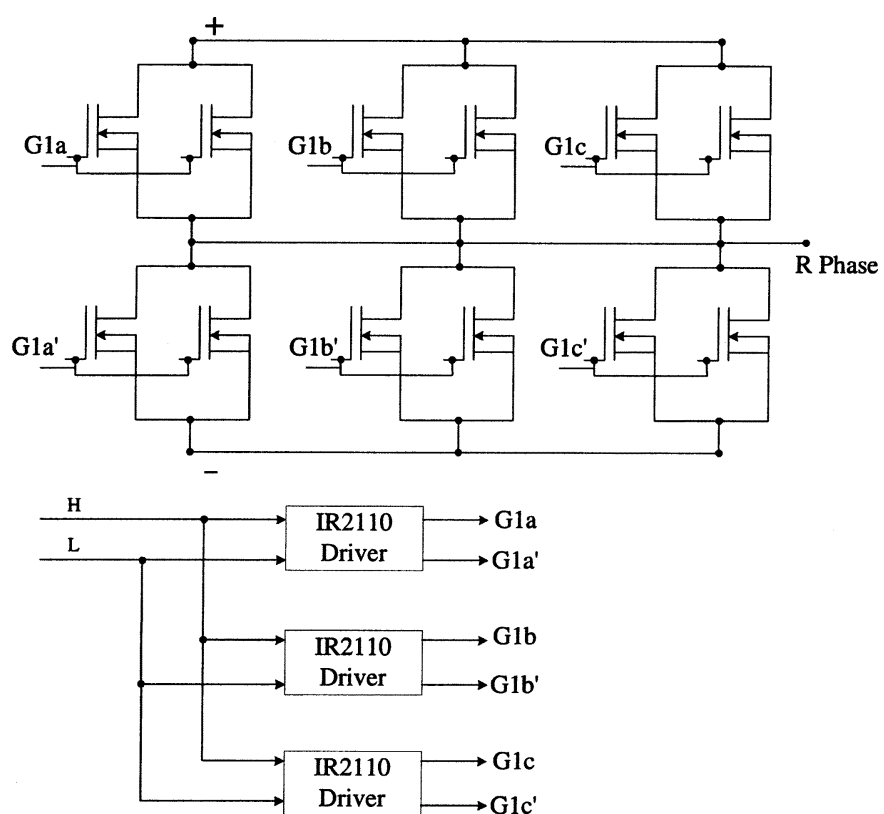

Fig. 21. Drive circuit arrangement for one leg of the power stage.

TABLE II

SUMMARY OF THE TESTED ISG SYSTEM

\begin{tabular}{|c|c|}
\hline Time required for cranking (Milliseconds) & 200 \\
\hline Dc bus voltage variation (Volts) & $22-43$ \\
\hline Peak torque at starting (Nm) & 130 \\
\hline Maximum peak phase current at starting (Amps, peak) & 800 \\
\hline Maximum peak phase current at generation (Amps, peak) & 220 \\
\hline Maximum dc battery current at cranking (Amps) & 500 \\
\hline Maximum dc battery current at generation (Amps) & 150 \\
\hline
\end{tabular}

\section{CONCLUSION}

This paper presents crankshaft mounted induction machine based ISG operation with the technique of DTC. Detailed experimental results verify and demonstrate the performance of the technique in different modes of ISG. Details of low voltage high current power module are given. The feature of OTFS mode of operation is also verified with experimental results.

\section{ACKNOWLEDGMENT}

The authors wish to thank the Staff and Management of the Advanced Engineering Center, M/S LUCAS-TVS Pvt., Ltd., for assistance and test facilities provided for carrying out the experimental tests on diesel engine.

\section{REFERENCES}

[1] J. G. Kassakian, J. M. Miller, and N. Traub, "Automotive power electronics up," IEEE Spectrum Mag., pp. 34-39, May 2000.

[2] J. G. Kassakian, "Automotive electrical systems - the power electronics market of the future," in Proc. IEEE Appl. Power Electron. Conf., 2000, vol. 1, pp. 3-9.
[3] SAE, "Transition to 42-Volt Electrical System," Tech. Rep. SP-1556, Society for Automotive Engineers, May 2000.

[4] C. Williams, "Comparison and review of electric machines for integrated starter generator applications," in Proc. IEEE 39th IAS Annu. Meeting, Conf., Oct. 3-7, 2004, vol. 1, pp. 386-396.

[5] P. J. McCleer, J. M. Miller, A. R. Gale, M. W. Degner, and F. Leonardi, "Nonlinear model amd momentary performance capability of cage induction machine used for combined ISA," IEEE Trans. Ind. Appl. Soc., vol. 37, no. 3, pp. 840-846, May/Jun. 2001.

[6] H. Rehman, X. Xu, N. Liu, G. S. Kahlon, and R. J. Mohan, "Induction machine drive system for Visteon integrated starter-alternator," in Proc. IEEE IECON'99, Nov. 29-Dec. 3 1999, vol. 2, pp. 636-641.

[7] M. Naidu and J. Walters, "A 4 KW, $42 \mathrm{~V}$ induction machine based power generation system with a diode bridge rectifier and a PWM inverter,' IEEE Trans. Ind. Appl., vol. 39, no. 5, pp. 1287-1293, Sep./Oct. 2003.

[8] S. Chen, B. Lequesne, R. R. Henry, Y. Xue, and J. J. Ronning, "Design and testing of belt driven induction starter-generator," IEEE Trans. Ind. Appl., vol. 38, no. 6, pp. 1525-1533, Nov./Dec. 2002.

[9] I. Takahashi and T. Noguchi, "A new quick response and high efficiency control strategy of induction machine," IEEE Trans. Ind. Appl., vol. IA-2, no. 5, pp. 820-827, Sep./Oct. 1986.

[10] M. Depenbrock, "Direct Self Control (DSC) of inverter fed induction motor," IEEE Trans. Ind. Appl., vol. 25, no. IA-2, pp. 257-264, Mar./ Apr. 1989.

[11] J. N. Nash, "Direct torque control of induction motor vector control without an encoder," IEEE Trans. Ind. Appl., vol. 33, no. 2, pp. 333-341, Mar./Apr. 1991.

[12] M. Shashidhar, "Induction Machine Based Integrated Starter Generator for Automobile Appllication," M.Sc. thesis, Dept. Elect. Eng., Indian Inst. Sci.., Bangalore, India, Aug. 2002.

[13] A. R. Beig, "Direct Torque Control of Induction Machine Using DSP," M.E. thesis, Dept. Elect. Eng., Indian Inst. Sci., Bangalore, India, Jan. 1998.

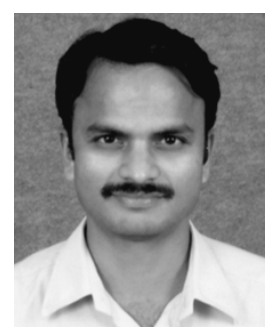

Amit Kumar Jain (S'04) was born in Bhilai, India, in 1975. He received the B.E degree in electrical engineering from the Shri Govindram Sakseria Institute of Technology and Science, Indore, India, in 1999 and the M.Sc. degree in electrical engineering from the Indian Institute of Science (I.I.Sc.), Bangalore, in 2004 where he is currently pursuing the Ph.D. degree.

After receiving the B.E. degree, he spent two and half years with the Department of Electrical Engineering, I.I.Sc, as a Project Staff Member. During this period he was involved with various research and development projects sponsored by leading companies such as, BARC, BEL, and Lucas-TVS Pvt Ltd. These projects are concerned with digital motor control of PMSM and induction machines for defence and automotive applications. His research interests are in the area of induction machine drives, permanent magnet machine drives, active filters, and converter design.

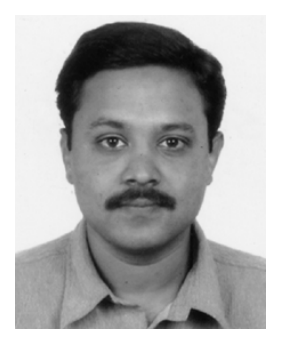

Shashidhar Mathapati was born in Gulbarga, India, in 1978. He received the B.E degree in electrical engineering fromthe PDA college of Engineering, Gulbarga, India, in 2000, the M.Sc. degree in electrical engineering from the Indian Institute of Science (I.I.Sc.), Bangalore, in 2002, and is currently pursuing the Ph.D. degree at the Department of Power Electronics and Electrical Drives, University of Paderborn, Paderborn, Germany.

After receiving the M.Sc. degree, he spent two years with Delphi automotive Systems, Bangalore, working on automotive electronics and a year with the Integrated Electric Company Pvt. Ltd., Bangalore, as a Design Engineer. His research interests are in the area of ac motor drives. 


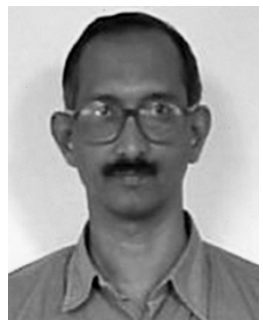

V. T. Ranganathan (M'86-SM'95) was born in Chennai, India, in 1955. He received the B.E and M.E degrees in electrical engineering from the Indian Institute of Science (I.I.Sc.), Bangalore, in 1977 and 1979, respectively, and the Ph.D degree from Concordia University, Montreal, QC, Canada, in 1984.

He joined the Electrical Engineering Department, I.I.Sc., in 1984 as an Assistant Professor and is currently a Professor. His research interests are in the area of power electronics and motor drives. $\mathrm{He}$ has made significant research contributions in the areas of vector control of ac drives, pulsewidth-modulation techniques, split-phase induction motor drives, and slip-ring induction motor drives. His work has led to a number of publications in leading journals, as well as patents. He is also active as a consultant to industry and has participated in a number of research and development projects in various areas, such as industrial drives, servo drives, traction drives, wind energy, and automotive applications.

Dr. Ranganathan received the Prize Paper Award from the Static Power Converter Committee of the IEEE Industry Applications Society in 1982, the Tata Rao Prize of the Institution of Engineers India from 1991 to 1992, the VASVIK Award in Electrical Sciences and Technology in 1994, and the Bimal Bose Award of the Institution of Electronics and Telecommunication Engineers, India in 2001. He is a Fellow of the Indian National Academy of Engineering and the Institution of Engineers, India.

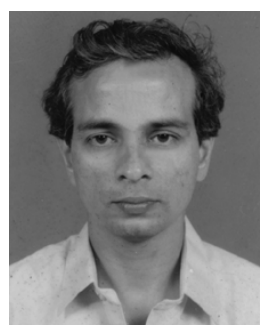

V. Narayanan received the B.Tech. and M.S. degrees in electrical engineering from Indian Institute of Technology, Chennai, in 1983 and 1996, respectively.

He is presently heading the Advanced Engineering Group, Research and Development Division, Lucas TVS Ltd., Chennai, India, as a Senior Manager. His areas of interest include design/simulation of electrical machines and power electronics for automotive applications. 